\title{
Does Time Since Immigration Modify Neighborhood Deprivation Gradients in Preterm Birth? A Multilevel Analysis
}

\author{
Marcelo Luis Urquia, John William Frank, \\ Rahim Moineddin, and Richard Henry Glazier
}

\begin{abstract}
Immigrants' health is jointly influenced by their pre- and post-migration exposures, but how these two influences operate with increasing duration of residence has not been well-researched. We aimed to examine how the influence of maternal country of birth and neighborhood deprivation effects, if any, change over time since migration and how neighborhood effects among immigrants compare with those observed in the Canadian-born population. Birth data from Ontario hospital records (2002-2007) were linked with an official Canadian immigration database (1985-2000). The outcome measure was preterm birth. Neighborhoods were ranked according to a neighborhood deprivation index developed for Canadian urban areas and collapsed into tertiles of approximately equal size. Time since immigration was measured from the date of arrival to Canada to the date of delivery, ranging from 1 to 22 years. We used cross-classified random effect models to simultaneously account for the membership of births $(N=83,233)$ to urban neighborhoods $(\mathrm{N}=1,801)$ and maternal countries of birth $(\mathrm{N}=168)$. There were no differences in preterm birth between neighborhood deprivation tertiles among immigrants with less than 15 years of residence. Among immigrants with 15 years of stay or more, the adjusted absolute risk difference (ARD\%, 95\% confidence interval) between high-deprived (tertile 3) and lowdeprived (tertile 1) neighborhoods was $1.86(0.68,2.98)$, while the ARD\% observed among the Canadian-born $(N=314,237)$ was $1.34(1.11,1.57)$. Time since migration modifies the neighborhood deprivation gradient in preterm birth among immigrants living in Ontario cities. Immigrants reached the level of inequalities in preterm birth observed at the neighborhood level among the Canadian-born after 14 years of stay, but neighborhoods did not influence preterm birth among more recent immigrants, for whom the maternal country of birth was more predictive of preterm birth.
\end{abstract}

KEYWORDS Neighborhoods, Immigrants, Urban, Preterm birth, Country of birth, Deprivation

\section{INTRODUCTION}

Socioeconomic gradients in birth outcomes are well documented. ${ }^{1-5}$ Associations between low socioeconomic position (SEP) and adverse birth outcomes have been

Urquia and Glazier are with the Centre for Research on Inner City Health, The Keenan Research Centre in the Li Ka Shing Knowledge Institute, St. Michael's Hospital, Toronto, ON, Canada; Frank is with the Scottish Collaboration for Public Health Research and Policy, University of Edinburgh, Edinburgh, UK; Moineddin and Glazier are with the Institute for Clinical Evaluative Sciences, Toronto, Canada; Moineddin and Glazier are with the Department of Family and Community Medicine, University of Toronto, Toronto, Canada.

Correspondence: Marcelo Luis Urquia, Centre for Research on Inner City Health, The Keenan Research Centre in the Li Ka Shing Knowledge Institute, St. Michael's Hospital, 30 Bond St, Toronto, ON M5C 1N8, Canada. (E-mail: marcelo.urquia@utoronto.ca) 
observed through a wide range of measures, such as individual income, education, occupation, or neighborhood material deprivation, and racial segregation. However, immigrants represent one major exception to this pattern, since several studies have not found socioeconomic gradients in birth outcomes in this group. ${ }^{6-13}$ Potential explanations of this anomaly include selective migration, low variability in socioeconomic status among immigrants, and group-level attributes such as a protective cultural orientation. ${ }^{6,12,14}$

It is also possible that the ability to detect socioeconomic gradients in birth outcomes among immigrants is affected by the prevailing absence of information on immigrants' duration of residence in the receiving country in previous studies. Time since migration may confound or modify SEP gradients among immigrants. Recent immigrants are more likely to be misclassified with respect to individual SEP measures because they experience a mismatch between their educational credentials and their initial occupations and labor market income, thus flattening the gradients. The use of area-based proxies for individual SEP may also result in misclassification since recent immigrants tend to settle in low-rental dwellings concentrated in poor neighborhoods, ${ }^{13,15}$ irrespective of their education or SEP in their home countries. In contrast, SEP measures can be theoretically expected to be more consistent among long-term immigrants via two non-exclusive pathways. First, long-term immigrants have gone through the adaptation process to the new physical and social environment and have reached a relatively stable position in the new society. By that time, their occupation, income and the characteristics of the residential environment in which immigrants live in may be more likely to reflect immigrants' true individual SEP. Second, although measurement of neighborhood SEP at the time of delivery is not affected by misclassification by time since immigration, some time is generally needed for environmental exposures, including neighborhood deprivation, to exert their effects on health. ${ }^{16}$ While neighborhoods have been found to have little, if any, influence on birth outcomes of recent immigrants, ${ }^{13,17}$ it remains to be established whether neighborhoods become influential among immigrants who have lived longer in the receiving country. This matter is relevant for the investigation of neighborhood effects on health, since immigrants can be regarded as a cohort exposed to a new residential environment after migration. Therefore, it is of more general interest to quantify the length of time it takes for neighborhood socioeconomic indices to predict birth outcomes for immigrant women.

From a life-course perspective, pre-migration exposures in the home country may influence immigrants' health long after their emigration, although it is not known how many years are needed for such influences to be "washed-out" in the case of birth outcomes, such as preterm birth.

We hypothesized that the influence of "place of residence" on preterm birth will be stronger with increasing length of residence in Ontario urban areas and therefore neighborhood deprivation gradients in preterm birth among immigrants will become more consistent with increasing time spent in the new country. Conversely, the influence of maternal "place of birth" was expected to diminish with increasing time spent in the receiving country.

We also compared neighborhood-deprivation gradients among immigrant subgroups with those observed in the Canadian-born population.

\section{METHODS}

This is a population-based study using administrative data linkages to relate delivery/birth data with maternal immigration characteristics. 
Ontario is Canada's most populous province (12.2 million in 2006) and receives annually about half of all immigrants to Canada (approximately 120,000 each year), with more than $90 \%$ of them concentrated in urban areas. The study population was composed of all 474,614 singleton live births born in Ontario hospitals to mothers living in any of the 11 Ontario Census Metropolitan Areas (Great Sudbury, Hamilton, Kingston, Kitchener, London, Oshawa, St. CatharinesNiagara, Ottawa-Gatineau, Thunder Bay, Toronto, and Windsor ${ }^{18}$ at the time of delivery, between April 1, 2002 and March 31, 2007.

Preterm birth and some maternal and obstetric characteristics were obtained from the Discharge Abstract Database of the Canadian Institute of Health Information that captures around $98 \%$ of all deliveries that occurred in the province. Birth data were limited to the most recent 5-year period available (April 1, 2002 to March 31, 2007) in order to ensure that the measurement of the outcomes was the same for all the study subjects and not affected by secular trends and changes in coding schemes and reporting practices over time. Data on immigrants' landings to Ontario were available for the calendar years 1985-2000 through the Landed Immigrant Data System, which is the official immigration registry compiled by Citizenship and Immigration Canada. Immigration data were probabilistically linked with the healthcare databases based on surname, given names, sex, and date of birth. Special algorithms to account for unique characteristics of foreign names (e.g., inversion of first and family name, standardization of names, conversion to upper case, diverse text functions) were incorporated into the linkage process. Different matching strategies were tried and records were classified as excellent matches, matches needed to be reviewed, and obvious non-matches. The last two groups were reviewed manually and added to a subsequent matching cycle. This strategy resulted in $84 \%$ of immigrants successfully matched to entries in the provincial healthcare registry. Matched and nonmatched individuals did not differ substantially across most characteristics in the immigrant dataset. ${ }^{19}$ Some non-matched immigrants may have moved back to their countries or to other provinces shortly after arrival and others may have been classified as non-immigrants. While this miscategorization may affect comparisons between immigrants and non-immigrants, comparisons made between immigrant groups are not likely to be biased because the reference group is internal to immigrants. To avoid misclassification of immigrant status regarding immigrants obtaining their permanent residence after December 31, 2000, we excluded 74,961 infants whose mothers were first registered into the provincial Health Insurance Plan after March 31, 2001 (to account for the 3-month registration waiting period for immigrants), who may have been newcomers either from abroad or from other provinces and who would have been otherwise classified as non-immigrants. After excluding another 2,183 records with missing or invalid information on the outcomes and covariates, the final population size for analyses was 397,470 births. These data were merged with small-area data (census tracts as neighborhoods) from the 2001 Canadian census to obtain a neighborhood deprivation measure.

Use of the data was approved by the Sunnybrook Health Sciences Centre and by the Research Ethics Board of the University of Toronto, Toronto, Ontario.

\section{Outcome}

Preterm birth is a major predictor of perinatal morbidity and mortality, and is associated with childhood disabilities, neurodevelopmental disorders, and adult onset of diseases. ${ }^{20,21}$ Preterm birth (PTB) was defined as a delivery before 37 completed weeks of gestation. Gestational age is largely estimated by ultrasound 
dating in Canada and finally determined by the attending physician's best interpretation of all of the clinical data, backed up by documentation from the nursing staff as a secondary source. ${ }^{22}$ In Ontario in 2006, $95 \%$ of women had their first ultrasound by week 20 of gestation. ${ }^{23}$

\section{Neighborhood Deprivation}

We used a material-deprivation score ${ }^{24}$ with mean 0 and standard deviation 1 based on information of the 2001 Census aggregated at the census tract level, which combined the following characteristics: percent of population below the Statistics Canada low income cutoff, percent of population 20 years and over without high school diploma, percent of single-parent families, percent of income comprised of government transfer payments, percent of population unemployed (15 years and over), and percent of homes needing major repairs. Census tracts are relatively stable urban neighborhoods with a typical population of 2,500-8,000 and are relatively homogeneous with respect to population characteristics and living conditions. Census tract boundaries have been found to correspond well to those of "natural" neighborhoods. ${ }^{25}$ Census tracts were ordered according to their material deprivation score and collapsed into three approximately equal-sized groups (tertiles).

\section{Immigrants' Duration of Residence}

Mothers were categorized as foreign-born if present in the immigration database. "Nonimmigrants" or "Canadian-born" included mostly the Canadian-born and a few immigrant women who obtained their permanent residence before 1985, whose immigration status could not be determined due to lack of data. We measured duration of residence in Canada as the difference between the date of delivery and the date of arrival, thus reflecting the time of exposure to the local environment. We used duration of residence as a continuous measure and also collapsed it in approximately 5-year duration groups (15 months -4 years, 5-9 years, $10-14$ years, and 15 years and more).

\section{Covariates}

Information from hospital records available for the entire study population was measured at the time of delivery/birth and included infant sex (male vs. female), maternal age at delivery $(15-19,20-24,25-29,35-39, \geq 40$ years vs. $30-34)$, and parity (primiparae versus multiparae; Table 1 ).

Information available for immigrants only was obtained from their landing records and last updated at the port of entry on the date of landing to Canada. With the exception of language knowledge, which was self-reported, the remaining information was ascertained based on legal documentation provided by the immigrants during their application processes.

Relevant covariates included maternal country of birth, age at arrival groups $(<12,12-18,19-25,26-30$, and $>30$ years), high school graduation (no versus yes), marital status (single, widowed, or separated versus married or common law), immigrant class (economic class, refugee status versus family class), and knowledge of either official Canadian language (none vs. English or French). Countries of birth were grouped into world regions using a modified version of the UNICEF classification (Appendix 1). ${ }^{26}$

\section{Analyses}

To determine neighborhood effects for each comparison group, we obtained separate variance estimates for non-immigrants and immigrants according to their 
TABLE 1 Characteristics of the study population by immigrant status, singleton live births, urban Ontario, 2002-2007

\begin{tabular}{|c|c|c|}
\hline & $\begin{array}{l}\text { Immigrants } \\
N(\%)\end{array}$ & $\begin{array}{l}\text { Canadian-born } \\
N(\%)\end{array}$ \\
\hline Total & $83,233(100)$ & $314,237(100)$ \\
\hline \multicolumn{3}{|l|}{ Country-level characteristics } \\
\hline \multicolumn{3}{|l|}{ Maternal regions of birth } \\
\hline Industrialized countries & $11,530(13.8)$ & \\
\hline East Europe/Central Asia & $6,173(7.4)$ & \\
\hline Caribbean & $10,588(12.7)$ & \\
\hline Latin America & $4,593(5.5)$ & \\
\hline East Asia/Pacific & $15,247(18.3)$ & \\
\hline South Asia & $22,518(27.1)$ & \\
\hline Middle East/North Africa & $6,174(7.4)$ & \\
\hline Sub-Saharan Africa & $6,410(7.7)$ & \\
\hline \multicolumn{3}{|l|}{ Neighborhood-level characteristics } \\
\hline \multicolumn{3}{|l|}{ Material deprivation (tertiles) } \\
\hline 1 Low deprivation & $24,685(29.7)$ & $139,548(44.4)$ \\
\hline 2 & $23,673(28.4)$ & $91,693(29.2)$ \\
\hline 3 High deprivation & $34,875(41.9)$ & $82,996(26.4)$ \\
\hline \multicolumn{3}{|l|}{ Individual-level characteristics } \\
\hline Preterm birth & $4,986(6.0)$ & $19,637(6.3)$ \\
\hline Male sex & $42,996(51.7)$ & $160,836(51.2)$ \\
\hline \multicolumn{3}{|l|}{ Maternal age group (years) } \\
\hline $15-19$ & $1,527(1.8)$ & $11,535(3.7)$ \\
\hline $20-24$ & $9,034(10.9)$ & $35,894(11.4)$ \\
\hline $25-29$ & $23,243(27.9)$ & $82,385(26.2)$ \\
\hline $30-34$ & $28,306(34.0)$ & $114,832(36.5)$ \\
\hline $35-39$ & $17,051(20.5)$ & $58,218(18.5)$ \\
\hline 40 and over & $4,072(4.9)$ & $11,373(3.6)$ \\
\hline Primiparous women & $30,420(36.6)$ & $146,253(46.5)$ \\
\hline No high school diploma ${ }^{a}$ & $52,735(63.4)$ & \\
\hline Single/divorced/separated ${ }^{a}$ & $46,658(56.1)$ & \\
\hline \multicolumn{3}{|l|}{ Immigrant class $^{\mathrm{a}}$} \\
\hline Economic class & $23,910(28.7)$ & \\
\hline Family class & $47,792(57.4)$ & \\
\hline Refugees & $11,531(13.9)$ & \\
\hline No knowledge of English or French ${ }^{\mathrm{a}}$ & $36,120(43.4)$ & \\
\hline \multicolumn{3}{|l|}{ Length of residence } \\
\hline $1-4$ years & $14,555(17.5)$ & \\
\hline $5-9$ years & $32,539(39.1)$ & \\
\hline 10-14 years & $23,827(28.6)$ & \\
\hline 15 years and more & $12,312(14.8)$ & \\
\hline
\end{tabular}

aThese variables were measured at the time of arrival to Canada

duration of residence by conducting stratified analyses. We used a two-level model for non-immigrants with births nested within neighborhoods (model 1), and crossclassified random effects models (CCREM) for immigrants (model 2), to account for the simultaneous membership of births to maternal countries of birth and neighborhoods, and stratified by duration of residence groups to obtain separate variance estimates at each length of residence. CCREM are appropriate to model 
non-nested data structures, ${ }^{27,28}$ such as ours. Immigrant mothers living in a particular neighborhood may have come from several different countries, and mothers coming from a particular country may settle in different neighborhoods. Thus, this data structure presents a cross-classification of countries and neighborhoods. Details of this approach are given elsewhere. ${ }^{17}$ For each model, the total variance of preterm birth was partitioned into the variance between maternal countries of birth and the variance between neighborhoods. $P$ values for the variance components were calculated using the Wald test (one-sided). ${ }^{27}$

To assess how the neighborhood deprivation gradient in preterm birth varied according to immigrant status and immigrants' duration of residence, we constructed an additional model for all immigrants (model 3). This was a CCREM with births nested within neighborhoods and maternal countries of birth, including a product term between duration subgroups and deprivation tertiles, and adjusted for infant sex, maternal age, parity, and socio-demographic and immigration characteristics that were only available for immigrants. In exploratory analyses, we examined the distribution of births across maternal countries of births and neighborhoods, by immigrant status and immigrants' duration of residence to ensure that the data met the minimum sample size requirements for multilevel logistic regression. ${ }^{29,30}$

From the logistic model, we calculated predicted probabilities of preterm birth and adjusted absolute risk differences in preterm birth (both expressed as percents) between neighborhood deprivation tertiles, with $95 \%$ confidence intervals using normal approximation. ${ }^{31}$ We chose to report absolute rather than relative measures of effect because absolute risk differences better reflect the excess population burden of the outcome attributable to differences in neighborhood deprivation.

In exploratory analyses restricted to immigrants, we tested whether the associations between duration of residence and neighborhood deprivation with preterm birth differed across maternal regions of birth and cohorts of arrival (pre 1988, 1989-1992, 1993-1996, and 1997-2000). Since none of these interactions were statistically significant, we therefore considered maternal regions of birth and cohorts of arrival as potential confounding factors. Cohort of arrival was dropped out because it was not associated with the outcome. We also performed sensitivity analyses considering the effect of age at arrival but this variable was not associated with preterm birth, particularly among young immigrants. Duration of residence was associated with preterm birth across strata of age at arrival and cohorts of arrival. An additional reason to exclude age at arrival is that this variable is a linear combination of maternal age at delivery and duration of residence, which were included in the adjusted models. We also explored whether year of birth was a confounder of the association between duration of residence and preterm birth, since secular increases in preterm birth rates have been reported in Canada. ${ }^{32}$ The association between year of birth and preterm birth disappeared after immigrants' duration of residence was added to the model but the unadjusted association between duration of residence and preterm birth did not change after year of birth was added to the model and therefore we dropped year of birth from the models.

\section{RESULTS}

Approximately $21 \%(N=83,233)$ of all singleton live births were born to immigrant women. These births were distributed across 1,801 neighborhoods and 168 
maternal countries of birth. Compared to the Canadian-born, immigrant mothers were somewhat older at delivery and had at least one previous live birth (Table 1). Immigrants were more likely to live in deprived neighborhoods than their nonimmigrant counterparts. The percentage of immigrants living in the most deprived tertile of neighborhoods $(41.9 \%$ in total) decreased somewhat with duration of residence $(46.0 \%$ among immigrants with less than 5 years of stay and $36.8 \%$ among those with 15 or more years).

Among Canadian-born women, there was significant variability in preterm birth across neighborhoods (Table 2). Births to immigrant women were widely distributed across maternal countries of birth and urban neighborhoods, although immigrants were not represented in some neighborhoods. The variability in preterm birth at the maternal country-level among immigrants, assessed by the country-level variance, decreased with increasing time of residence in Canada and was no longer statistically significant after 14 years of stay. Conversely, the neighborhood variance was not significant up to 14 years of immigrants' residence but became highly statistically significant among those immigrants with 15 or more years of stay.

Model 1 shows the neighborhood deprivation gradient in preterm birth among the Canadian-born (Table 3). Model 3 was a CCREM with all immigrants including an interaction term between neighborhood deprivation tertiles and duration of residence, which was statistically significant $(p=0.039)$, indicating that differences in preterm birth between neighborhood deprivation tertiles varied with duration of residence (Table 3 and Figure 1). Consistent with the results of Table 2, there were no differences in preterm birth between deprivation tertiles up to 14 years of stay (Table 3). Preterm birth rates linearly increased with advanced duration of residence across all neighborhood tertiles (Figure 1), with the exception of immigrants living in the least deprived tertile of neighborhoods, for whom the increase in PTB slowed down at about 10-14 years of residence. While recent immigrants, regardless of the type of neighborhood they lived in, had lower PTB than non-immigrants, long-term immigrants ( $\geq 15$ years) had worse outcomes than their similar SEP, non-immigrant counterparts (Table 3 and Figure 1).

TABLE 2 Number of births, maternal countries of birth, neighborhoods, and variance components for preterm birth, by immigrant status and immigrants' duration of residence, singleton live births, urban Ontario, 2002-2007

\begin{tabular}{|c|c|c|c|c|c|}
\hline & Births & Countries & $\begin{array}{l}\text { Census- } \\
\text { tracts }\end{array}$ & $\begin{array}{l}\text { Country-level } \\
\text { Variance (SE) }\end{array}$ & $\begin{array}{l}\text { Census-tract level } \\
\text { Variance (SE) }\end{array}$ \\
\hline Model 1 Canadian-born ${ }^{\mathrm{a}}$ & 314,237 & 1 & 1,801 & & $0.023^{* * *}(0.004)$ \\
\hline \multicolumn{6}{|c|}{ Model 2 Immigrants stratified by duration of residence ${ }^{b}$} \\
\hline$<5$ years & 14,555 & 148 & 1,472 & $0.125^{*}(0.067)$ & $0.029(0.061)$ \\
\hline $5-9$ years & 32,539 & 162 & 1,649 & $0.101 * *(0.040)$ & $0.015(0.019)$ \\
\hline 10-14 years & 23,827 & 161 & 1,622 & $0.045^{*}(0.023)$ & $0.009(0.022)$ \\
\hline$\geq 15$ years & 12,312 & 133 & 1,523 & $0.008(0.022)$ & $0.125^{* *}(0.054)$ \\
\hline
\end{tabular}

\footnotetext{
${ }^{a}$ Two-level model adjusted for infant sex, maternal age, and parity

${ }^{b}$ Cross-classified random effects models adjusted for infant sex, maternal age, parity, immigrant class, knowledge of English or French, high school graduation, maternal world region of birth, and marital status ${ }^{*} p<0.05,{ }^{* *} p<0.01,{ }^{* * *} p<0.001$ ( $p$ values for variances are one-sided)
} 


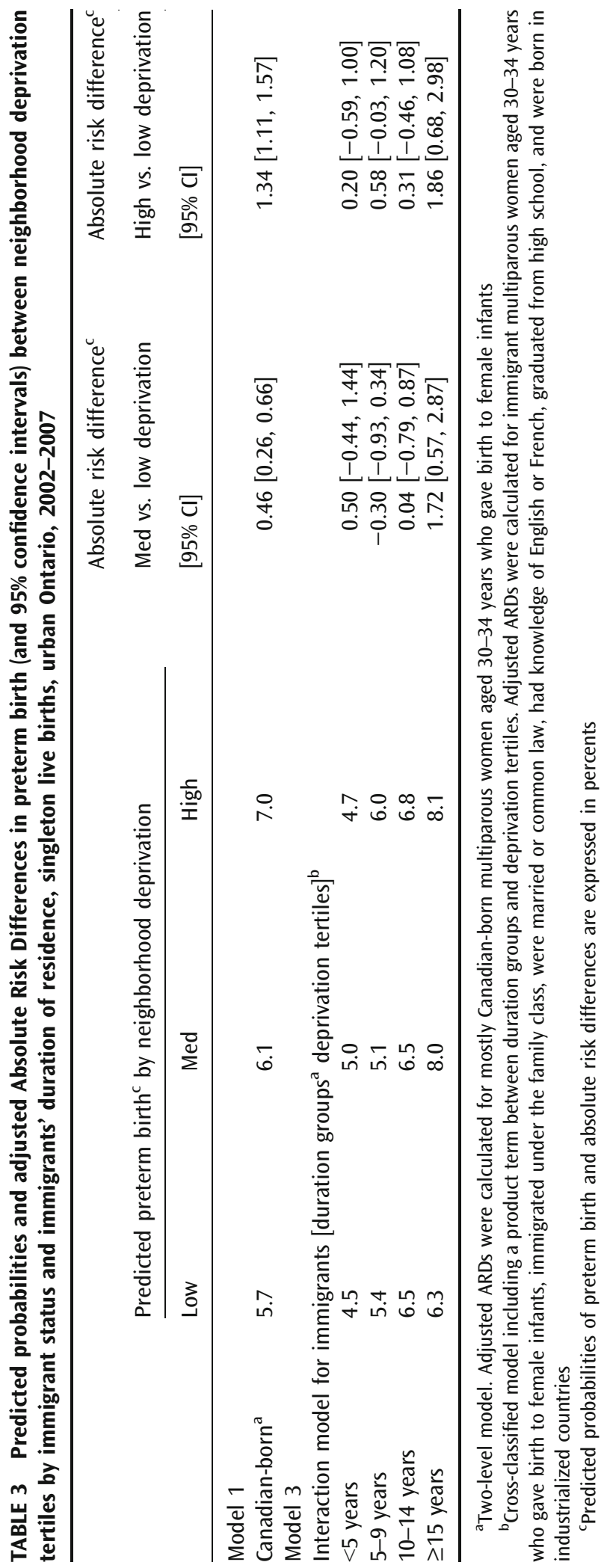




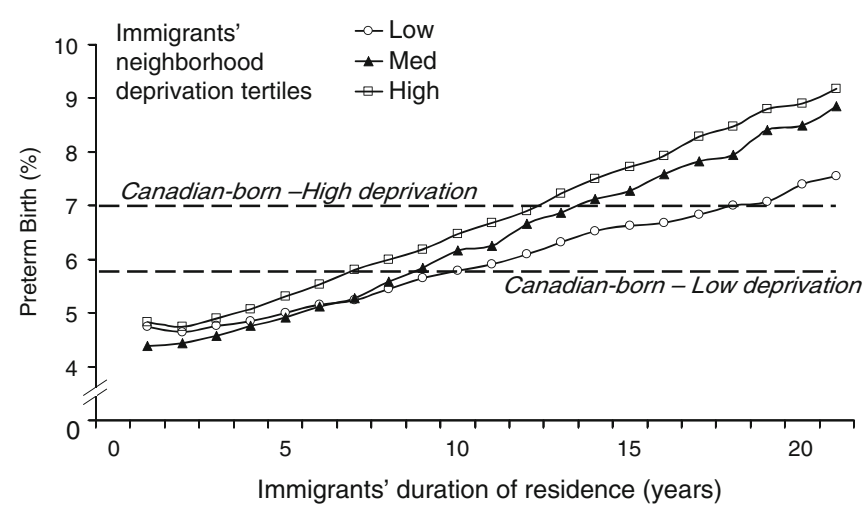

FIGURE 1. Preterm birth rates among immigrants by years of residence and neighborhood deprivation tertiles and among the Canadian-born (high- and low-deprivation tertiles), urban Ontario, singleton live births 2002-2007.

\section{DISCUSSION}

\section{Main Findings}

This population-based study shows that immigrants' duration of residence in Ontario cities modifies the influence of both the maternal "place of birth" and "place of residence at delivery" on preterm birth. Maternal country of birth was influential for preterm birth up to 14 years of residence in Canada but neighborhoods were not. This pattern was reversed after 14 years of residence, when the association between neighborhood deprivation and preterm birth among immigrants reached the level of inequalities observed among the Canadian-born population.

\section{Strengths and Limitations}

This study has some key strengths. This is a population-based study with almost complete coverage of the target population, including a large and diverse immigrant population. Unlike in many studies, immigration status, country of origin, and time since arrival to delivery were not self-reported but ascertained through the governmental computerized immigration database, which is assumed to be accurate and complete because of its associated legal use, although it has not been validated. Our study is unique in its ability to accurately measure duration of residence over 20 years. We used an appropriate statistical method that prevents cross-level confounding between neighborhoods, countries, and individuals.

This study also has some limitations. Although immigration data were of good quality, some variables were measured at arrival and not at delivery. Marital status and maternal education may have changed for some women, especially for young women at arrival who may have become married and more educated with longer duration of residence. Misclassification of these characteristics may have affected the efficiency of adjustment in multivariate models. However, we performed secondary analyses restricted to women aged 20 and more, whose education and marital status are less likely to be misclassified, but the observed associations did not disappear. We lacked data on these characteristics for the Canadian-born, thus preventing their inclusion in multivariable models. Potential confounding by individual-level characteristics in multilevel studies is always a possibility. We also lacked data on some important predictors of the outcomes, such as maternal anthropometry, 
tobacco smoking status, and other health behaviors. However, health behaviors are conceptualized as mediators rather than confounders of the association between duration of residence and birth outcomes. ${ }^{10,33,34}$ Finally, the immigration data available covered permanent visas issued in the period 1985-2000. Although we avoided misclassification of immigrant status after the year 2000 by excluding newcomers to Ontario, as assessed by first-time registrations to the universal provincial healthcare plan, we could not indirectly determine immigrant status prior to 1985 because the current provincial healthcare registry was set up in 1991 and the dates of first time registrations were set to the date the registry started. Therefore, immigrants whose permanent visa was issued before 1985 were misclassified as non-immigrants. Although the number of such false non-immigrants is supposed to be small, since the number of births to immigrant women sharply declined after 14 years of residence in Canada, they may have biased somewhat our results. On one hand, since preterm birth rates were higher, and inequalities in preterm birth larger, in the included long-term immigrants than among more recent immigrants, the inclusion of immigrants with even longer stay in Canada would have probably led to stronger associations, assuming a constant rate of increase in preterm birth rates with length of stay. On the other hand, the inclusion of long-term immigrants in the non-immigrant group may have confounded the SEP gradients among the Canadian-born, although only slightly due to the disproportionately larger size of the host population. A related limitation is that we did not have information to account for the ethnic heterogeneity in the non-immigrant group.

Since immigrants giving birth later in the study period (e.g., in 2007) lived in Canada for at least 7 years (arrived in or before 2000), for some women duration of residence was dependent in part on the year in which the birth occurred. This resulted in underrepresentation of recent immigrants in our study. However, this was not likely to have biased our results because year of birth was not a confounder of the association between duration of residence and preterm birth. Within every year of birth, we observed a linear increase in the risk of preterm birth, irrespective of the range of duration of residence that existed at each year of birth.

Finally, illegal immigrants are not captured by this linkage since the immigration database is composed of immigrants who legally applied for residence to Canada and the provincial healthcare registry includes residents with valid healthcard numbers. Although accurate estimates of illegal migration in Canada are not possible due to data limitations, ${ }^{35}$ the number of illegal immigrants is supposed to be small. In 2007, the Canada Border Services Agency determined that there were about 63,000 individuals with either enforceable removal orders or outstanding immigration warrants for removal. ${ }^{36}$ Although this may represent a conservative estimate of the total number of illegal immigrants in Canada, and its distribution by sex and age is not known, it is unlikely that illegal immigrant women of reproductive age represent an important public health problem in Ontario.

These findings may not be generalizable to illegal immigrants, to rural settings, or to other urban settings characterized by low immigration or immigration patterns dominated by a few distinct national or ethnic groups.

\section{Consistency with Other Studies}

Our findings are consistent with previous studies reporting the absence of associations between neighborhood measures and birth outcomes among recent immigrants. ${ }^{13,17}$ Other studies including all immigrants did not find associations between measures of SEP and birth outcomes either. ${ }^{6-12}$ This may be due to the fact that the majority of 
births to immigrants occur a few years after arrival. If the association is only found among long-term immigrants, then pooling together all immigrants may result in a dilution of such an effect. This suggests that only by examining effect modification of SEP by duration is it possible to reveal the observed pattern.

Our findings regarding the deterioration of preterm birth among immigrants with increasing duration of residence are in line with several studies conducted in North America and Britain, showing parallel increases in adverse birth outcomes and related risk factors such as tobacco smoking, alcohol drinking, physical inactivity, and obesity. ${ }^{34,37-40}$

\section{Interpretation}

As our neighborhood measures were based on the mothers' residence at the time of delivery and many may have moved since arrival, our findings should be interpreted with certain caution. The lack of information on immigrants' residential mobility prevents us from concluding that the observed neighborhood deprivation gradients in preterm birth among long-term immigrants were entirely due to cumulative exposure to neighborhood deprivation levels. However, it is likely that many immigrants living in deprived neighborhoods after 14 years of stay may have lived in the same or in other deprived neighborhoods throughout all their stay in Canada. The proportion of immigrants living in the most deprived tertile of neighborhoods was still high among those with 15 years of stay or more $(37 \%)$ compared to immigrants with less than 5 years of stay $(46 \%)$. These findings are consistent with studies showing that most residential mobility takes place between neighborhoods of similar characteristics. ${ }^{41}$

If neighborhood deprivation is used as a proxy for individual SEP rather than as an exposure on its own, the type of neighborhoods in which mothers lived at delivery may be conceptualized as a marker of the socioeconomic position achieved by that time. In any case, our findings imply that neighborhood measures are not good predictors of birth outcomes among recent immigrants. However, these new findings suggest that neighborhoods become predictive of preterm birth with prolonged immigrant residence ( $\geq 15$ years).

Indeed, the neighborhood deprivation gradient in preterm birth among immigrants with 15 years or more in Canada was of similar magnitude to the gradient observed among the Canadian-born population. This finding may be explained by the "segmented assimilation hypothesis" that states that immigrants are assimilated into the stratification system of the receiving society. ${ }^{42}$ However, and unlike the dose-response gradient for SEP observed among the Canadian-born, the gradient among immigrants was not linear. There was virtually no difference between the outcomes of long-term immigrants living in medium- and high-deprived neighborhoods. Only long-term immigrants living in the least deprived tertile of neighborhoods stood apart from the rest.

Our findings also revealed that the impact of material deprivation on immigrants' preterm birth was modest compared to the deleterious effects of duration of residence. Living in advantaged neighborhoods somewhat attenuated, but did not prevent, the gradual rise of preterm birth among long-term immigrants compared with more recent immigrants. In a life-course approach, this may suggest that a place to intervene could be among young immigrants, since this is the population that is more likely to be delivering 15 or more years later. In addition, as the association between time since immigration and preterm birth was linear, another place to intervene is among all immigrants upon arrival, irrespective of their 
age. Numerous studies had reported declining immigrant health with increasing time spent in developed countries, generally linked to deterioration of health behaviors. ${ }^{37-40}$ Our findings further suggest that living in deprived neighborhoods may contribute to exacerbate that deleterious trend. However, potential interventions should be informed by further research aimed at better understanding what specific pathways are involved in the deterioration of preterm birth rates with prolonged stay, after immigrants' arrival in Canada.

\section{CONCLUSION}

Time since migration modifies the neighborhood deprivation gradient in preterm birth among immigrants living in Ontario cities. Neighborhood deprivation does not appear to matter for immigrants before 15 years of stay. During that period, preterm birth among immigrants is better predicted by the maternal country of birth. After that period, the pattern is reversed and immigrants reached the level of inequalities in preterm birth observed at the neighborhood level among the Canadian-born. The opposite pattern was found for the maternal "place of birth," which was no longer predictive of preterm birth among long-term immigrants. The combination of prolonged duration of residence in Canada and neighborhood deprivation characterizes immigrant women at higher risk of delivering preterm infants.

\section{ACKNOWLEDGMENTS}

This study was supported by the Institute for Clinical Evaluative Sciences (ICES), which is funded by an annual grant from the Ontario Ministry of Health and LongTerm Care (MOHLTC). The opinions, results, and conclusions reported in this paper are those of the authors and are independent from the funding sources. No endorsement by ICES or the Ontario MOHLTC is intended or should be inferred. MLU was supported by personal research grant [CIHR IOP-44972] of JWF, Canadian Institutes of Health Research.

OPEN ACCESS This article is distributed under the terms of the Creative Commons Attribution Noncommercial License which permits any noncommercial use, distribution, and reproduction in any medium, provided the original author(s) and source are credited.

\section{APPENDIX 1: COUNTRY CLASSIFICATION}

Industrialized countries

Andorra

Australia

Austria

Belgium

Canada

Czech Republic

Denmark

Estonia

Finland

France 
Germany

Greece

Hong Kong, China

Hungary

Iceland

Ireland

Israel

Italy

Japan

Latvia

Lithuania

Luxembourg

Netherlands

New Zealand

Norway

Poland

Portugal

Republic of Korea

San Marino

Slovakia

Slovenia

Spain

Sweden

Switzerland

Turkey

United Kingdom

United States of America

Central \& East Europe

Albania

Armenia

Azerbaijan

Belarus

Bosnia and Herzegovina

Bulgaria

Croatia

Georgia

Kazakhstan

Kyrgyzstan

Macedonia (The former Yugoslav Republic of)

Moldova

Montenegro

Romania

Russian Federation

Serbia

Tajikistan

Turkey

Turkmenistan

Ukraine

Uzbekistan 
Middle East \& North Africa

Algeria

Bahrain

Djibouti

Egypt

Iran (Islamic Republic of)

Iraq

Jordan

Kuwait

Lebanon

Libyan Arab Jamahiriya

Morocco

Occupied Palestinian territory

Oman

Qatar

Saudi Arabia

Sudan

Syrian Arab Republic

Tunisia

United Arab Emirates

Yemen

Sub-Saharan Africa

Eastern and Southern Africa

Angola

Botswana

Burundi

Comoros

Eritrea

Ethiopia

Kenya

Lesotho

Madagascar

Malawi

Mozambique

Namibia

Rwanda

Seychelles

Somalia

South Africa

Swaziland

Tanzania (United Republic of)

Uganda

Zambia

Zimbabwe

West and Central Africa

Benin

Burkina Faso 
Cameroon

Cape Verde

Central African Republic

Chad

Congo

Congo (Democratic Republic of the)

Côte d'Ivoire

Equatorial Guinea

Gabon

Gambia

Ghana

Guinea

Guinea-Bissau

Liberia

Mali

Mauritania

Niger

Nigeria

Sao Tome and Principe

Senegal

Sierra Leone

Togo

Caribbean

Antigua and Barbuda

Barbados

Belize

British Virgin Islands

Dominica

Grenada

Guyana

Haiti

Jamaica

Montserrat

Saint Kitts and Nevis

Saint Lucia

Saint Vincent and the Grenadines

Suriname

Trinidad and Tobago

Turks and Caicos Islands

Hispanic America

Argentina

Bolivia

Brazil

Chile

Colombia

Costa Rica

Cuba

Dominican Republic 
Ecuador

El Salvador

Guatemala

Honduras

Mexico

Nicaragua

Panama

Paraguay

Peru

Uruguay

Venezuela (Bolivarian Republic of)

East Asia \& Pacific

Cambodia

China

Cook Islands

Fiji

Indonesia

Kiribati

Korea (Democratic People's Republic of)

Lao People's Democratic Republic

Malaysia

Marshall Islands

Micronesia (Federated States of)

Mongolia

Myanmar

Nauru

Niue

Palau

Papua New Guinea

Philippines

Samoa

Solomon Islands

Thailand

Timor-Leste

Tokelau

Tonga

Tuvalu

Vanuatu

Vietnam

South Asia

Afghanistan

Bangladesh

Bhutan

India

Maldives

Nepal

Pakistan

Sri Lanka 


\section{REFERENCES}

1. Grady SC, McLafferty S. Segregation, nativity, and health: reproductive health inequalities for immigrant and Native-born black women in New York City. Urban Geogr. 2007;28:377-397.

2. Kramer MS, Seguin L, Lydon J, Goulet L. Socio-economic disparities in pregnancy outcome: why do the poor fare so poorly? Paediatr Perinat Epidemiol. 2000;14:194-210.

3. Krieger N, Chen JT, Waterman PD, Soobader MJ, Subramanian SV, Carson R. Choosing area based socioeconomic measures to monitor social inequalities in low birth weight and childhood lead poisoning: the Public Health Disparities Geocoding Project (US). J Epidemiol Community Health. 2003;57:186-199.

4. Messer LC, Vinikoor LC, Laraia BA, et al. Socioeconomic domains and associations with preterm birth. Soc Sci Med. 2008;67:1247-1257.

5. O'Campo P, Burke JG, Culhane J, et al. Neighborhood deprivation and preterm birth among non-Hispanic black and white women in eight geographic areas in the United States. Am J Epidemiol. 2008;167:155-163.

6. Acevedo-Garcia D, Soobader MJ, Berkman LF. The differential effect of foreign-born status on low birth weight by race/ethnicity and education. Pediatrics. 2005;115:e20-e30.

7. David RJ, Collins JW Jr. Differing birth weight among infants of US-born blacks, Africanborn blacks, and US-born whites [see comment]. N Engl J Med. 1997;337:1209-1214.

8. Fang J, Madhavan S, Alderman MH. Low birth weight: race and maternal nativityimpact of community income. Pediatrics. 1999;103:E5.

9. Gould JB, Madan A, Qin C, Chavez G. Perinatal outcomes in two dissimilar immigrant populations in the United States: a dual epidemiologic paradox. Pediatrics. 2003;111: e676-e682.

10. Landale NS, Oropesa RS. Gorman BK. Immigration and infant health:birth outcomes of immigrant and native-born women. In: Children of Immigrants: Health, Adjustment and Public Assistance. Washington, DC: National Academy Press; 1999:244-285.

11. Madan A, Palaniappan L, Urizar G, Wang Y, Fortmann SP, Gould JB. Sociocultural factors that affect pregnancy outcomes in two dissimilar immigrant groups in the United States. J Pediatr. 2006;148:341-346.

12. Pearl M, Braveman P, Abrams B. The relationship of neighborhood socioeconomic characteristics to birthweight among 5 ethnic groups in California. Am J Public Health. 2001;91:1808-1814.

13. Urquia M, Frank J, Glazier R, Moineddin R. Birth outcomes by neighbourhood income and recent immigration in Toronto. Health Rep. 2007;18:1-10.

14. Cervantes A, Keith L, Wyshak G. Adverse birth outcomes among native-born and immigrant women: replicating national evidence regarding Mexicans at the local level. Matern Child Health J. 1999;3:99-109.

15. Galarneau D, Morissette R. Immigrants: settling for less? Perspect Labour Income. 2004;5:5-16.

16. O'Campo P. Invited commentary: advancing theory and methods for multilevel models of residential neighborhoods and health. Am J Epidemiol. 2003;157:9-13.

17. Urquia M, Frank J, Glazier R, Moineddin R, Matheson F, Gagnon A. Neighborhood context and infant birthweight among recent immigrant mothers: a multilevel analysis. Am J Public Health. 2009;99:285-293.

18. Statistics Canada. The Classification. Ottawa, Canada: Statistics Canada (Catalogue number: 12-571-XIE); 2007. Standard Geographical Classification (SGC). Volume 1.

19. Desmeules M, McDermott S, Cao Z, et al. Immigrant health and health care utilization in Canada: phase II of the National Immigrant Health Initiative. Final report submitted to the Canadian population health initiative, Ottawa; 2004.

20. Committee on Understanding Premature Birth and Assuring Healthy Outcomes. Preterm birth: causes, consequences, and prevention. Washington, DC: National Academies Press; 2007. 
21. Saigal S, Doyle LW. An overview of mortality and sequelae of preterm birth from infancy to adulthood. Lancet. 2008;371:261-269.

22. Canadian Institute for Health Information. DAD Abstracting Manual (for use with ICD10-CA/CCI) 2006. Ottawa, Canada: Canadian Institute for Health Information; 20062007:1-524.

23. Public Health Agency of Canada. What mothers say: the Canadian maternity experiences survey. Ottawa, Canada: Public Health Agency of Canada; 2009.

24. Matheson FI, Moineddin R, Dunn JR, Creatore MI, Gozdyra P, Glazier RH. Urban neighborhoods, chronic stress, gender and depression. Soc Sci Med. 2006;63:2604-2616.

25. Ross NA, Tremblay SS, Graham K. Neighbourhood influences on health in Montreal, Canada. Soc Sci Med. 2004;59:1485-1494.

26. United Nations Children's Fund. Information by country and programme. Countries by region. http://www.unicef.org/infobycountry/index.html. (Accessed December 15, 2008).

27. Hox J. Multilevel analysis. Techniques and applications. Mahwah, NJ: Lawrence Erlbaum Associates; 2002.

28. Raudenbush S, Bryk A. Hierarchical linear models. Applications and data analysis methods. Thousand Oaks, CA: Sage Publications; 2002.

29. Maas CJM, Hox JJ. Sufficient sample sizes for mutilevel modeling. Methodology. 2005;1:86-92.

30. Moineddin R, Matheson FI, Glazier RH. A simulation study of sample size for multilevel logistic regression models. BMC Med Res Methodol. 2007;7:34.

31. Austin PC. Absolute risk reductions, relative risks, relative risk reductions, and numbers needed to treat can be obtained from a logistic regression model. J Clin Epidemiol. 2010;63:2-6.

32. Public Health Agency of Canada. Canadian Perinatal Health Report, 2008 ed. Ottawa, Canada: Public Health Agency of Canada; 2008.

33. Crump C, Lipsky S, Mueller BA. Adverse birth outcomes among Mexican-Americans: are US-born women at greater risk than Mexico-born women? Ethn Health. 1999;4:2934.

34. Scribner R, Dwyer JH. Acculturation and low birthweight among Latinos in the Hispanic HANES. Am J Public Health. 1989;79:1263-1267.

35. Reitz J. Immigrant employment success in Canada, part I: individual and contextual causes. J Int Migr Integr. 2007;8:11-36.

36. Office of the Auditor General of Canada. 2008 May Report of the Auditor General of Canada. Ottawa, Canada: Office of the Auditor General of Canada; 2008.

37. Hawkins SS, Lamb K, Cole TJ, Law C. Influence of moving to the UK on maternal health behaviours: prospective cohort study. BMJ. 2008;336:1052-1055.

38. Hyman I, Dussault G. Negative consequences of acculturation on health behaviour, social support and stress among pregnant Southeast Asian immigrant women in Montreal: an exploratory study. Can J Public Health. 2000;91:357-360.

39. McDonald JT, Kennedy S. Is migration to Canada associated with unhealthy weight gain? Overweight and obesity among Canada's immigrants. Soc Sci Med. 2005;61:2469-2481.

40. Zambrana RE, Scrimshaw SC, Collins N, Dunkel-Schetter C. Prenatal health behaviors and psychosocial risk factors in pregnant women of Mexican origin: the role of acculturation. Am J Public Health. 1997;87:1022-1026.

41. South SJ, Crowder K, Chavez E. Exiting and entering high-poverty neighborhoods: Latinos, Blacks and Anglos compared. Soc Forces. 2005;82:873-900.

42. Zhou M. Segmented assimilation: issues, controversies, and recent research on the new second generation. Int Migr Rev. 1997;31:975-1008. 